\title{
Evaluation of Functionally Graded Ceramic Crucible for Induction Melting of TiAl Based Alloys
}

\author{
Fernando Gomes $^{1 a}$, Joaquim Barbosa ${ }^{1, b}$ and Carlos Silva Ribeiro ${ }^{2, c}$ \\ ${ }^{1} \mathrm{CT} 2 \mathrm{M}$ - Centre for Mechanical and Materials Technologies, Universidade do Minho \\ 4800-058 Guimarães, Portugal \\ ${ }^{2}$ FEUP, Departamento de Engenharia Metalúrgica e de Materiais, 4200-465 Porto, Portugal \\ afgomes@uminho.pt, ${ }^{\text {b } k i m @ d e m . u m i n h o . p t, ~}{ }^{\text {cs }}$ ribeiro@fe.up.pt
}

Keywords: Crucible; Titanium; Melting

\begin{abstract}
During the last years a very significant effort to develop a melting crucible for induction melting of Ti based alloys at competitive cost has been carried out by many researchers, where the authors are included. Results obtained so far have shown that no material accomplishes the melting crucibles two main demands: inertness facing titanium alloys and suitable/enough thermal-shock resistance. Until now, yttrium and calcium oxides were those materials that performed best on what concerns to thermodynamic stability. However, in both cases, crucibles thermal-shock resistance was very poor, and there are references to crucibles that cracked during melting. Besides, calcium oxide reveals manipulation problems, due to its high higroscopicity.

This paper concerns to the evaluation of zircon based crucibles with $\mathrm{Y}_{2} \mathrm{O}_{3}$ inner layer for induction melting of TiAl based alloys. A novel multi layered crucible production technique based in a centrifugally assisted slip casting process followed by a sintering operation is described, and results concerning to crucibles porosity and wall composition and morphology are presented.

Crucibles obtained in different processing conditions were used to melt a Ti48Al alloy which was poured in graphite moulds. Experimental results include alloy chemical contamination with residual elements, mainly yttrium and oxygen, microhardness measurement and the presence of yttrium oxide and zircon inclusions in the cast samples. Results concerning to the crucibles behaviour are also presented with particular attention to cracks development.

The $\mathrm{Y}_{2} \mathrm{O}_{3}$ crucible layer was found to suffer some erosion and be slightly dissolved by the molten alloy and the extent of those phenomena depends on the porosity of the layer surface, for fixed experimental melting conditions.
\end{abstract}

\section{Introduction}

With advances in extraction and production technologies and ever increasing fuel prices the advantage of using lightweight materials such as aluminium, magnesium and titanium alloys in automobiles continues to increase, particularly for the first two. On this context, as a result of a high strength-to-weight ratio and excellent mechanical and corrosion properties at high temperatures, titanium aluminides continue to be referred to as the "dream alloys" to replace traditional superalloys and steels in high temperature applications [1-3], not only in the automotive industry but also for aeronautical and aerospace applications. However, due to its high cost, current use of titanium aluminides is limited to applications where it is the only material that fulfils the technical requirements/specifications, or the cost factor is not a constraint. Examples of that are exhaust valves and turbocharger wheels of top models and racing cars and motorbikes [2,4], components for some military equipment like the Advanced Tactical Fighter F-22 Raptor [5] and aerospace applications.

Current production routes of TiAl components are limited to forging, powder metallurgy and casting. The first two are very prone to chemical and microstructure heterogeneity and powder metallurgy is highly expensive and limited to simple geometries. Casting, using induction skull melting (ISM) and the investment casting moulding process is the most versatile technology to manufacture intermetallic components. However, ISM has a high impact in the castings final cost 
and promote high level of castings rejections, mainly due to the difficulty to achieve suitable superheating, which is overcome by using high mould preheat temperatures. However, titanium aluminides are extremely reactive materials, and this solution tends to increase metal/mould interaction leading to oxygen pickup from the mould walls, which dissolves interstitially, leading to a strong hardness increase and alloy embrittlement.

The replacement of ISM for the traditional ceramic crucible induction melting process would be a solution to decrease production costs, but until today a suitable material for crucibles production has not been found yet. Alloy/crucible interactions are always present into a certain extent, leading to alloy contamination and consequent chemical heterogeneity and development of solidification defects in castings.

During more than two decades significant research effort aiming the development of a suitable ceramic crucible to melt titanium alloys has been carried out. Different oxides, carbides, borides and sulphides have been evaluated but results in general have been reported unsatisfactory [6] due to chemical incompatibility with the cast alloys and/or poor thermal-shock resistance of the crucibles that led to crack development and crucibles destruction. Among every tested material, $\mathrm{CaO}$ [7-9] and $\mathrm{Y}_{2} \mathrm{O}_{3}$ [10-13] were found to perform best, particularly $\mathrm{Y} 2 \mathrm{O} 3$. However, references to manipulation difficulties associated to the high higroscopicity of $\mathrm{CaO}$ and a slight reaction with the alloys for both $\mathrm{CaO}$ and $\mathrm{Y}_{2} \mathrm{O}_{3}$ still persist. Moreover, $\mathrm{Y}_{2} \mathrm{O}_{3}$ is an extremelly high cost material. Non-oxide materials like AIN and BN have recently been evaluated by Kartavykh and co-authors [14,15], and AlN was found to perform quite well, leading to non-contaminated castings [15].

During the last years, the authors have developed extensive research work on this field, and a reliable melting and moulding technique, using ceramic materials, has been developed. On this work the manufacturing technique of a multi-layer crucible and its behaviour when melting Ti-48Al alloys are presented and the results related with the processing conditions.

\section{Experimental Proceeding}

Crucibles Production. The crucible set consisted of two crucibles: one pouring crucible with lip, made of $\mathrm{ZrO}_{2} \cdot \mathrm{SiO}_{2}$, and a melting crucible placed inside of it. The melting crucible was a $\mathrm{ZrO}_{2} \cdot \mathrm{SiO}_{2}$ base crucible with an $\mathrm{Y}_{2} \mathrm{O}_{3}$ inner layer. The reasons for this solution were twofold: very low cost and high thermal-shock strength of $\mathrm{ZrO}_{2} \cdot \mathrm{SiO}_{2}$ and high thermodynamics stability of $\mathrm{Y}_{2} \mathrm{O}_{3}$ against Ti alloys. The pouring crucible $(\varnothing 60 \mathrm{~mm} \times 140 \mathrm{~mm}$ ) was produced by slip casting using an emulsion of $0.1-10 \mu \mathrm{m}$ grain size $\mathrm{ZrO}_{2} \cdot \mathrm{SiO}_{2}$ in water and fired at $1500^{\circ} \mathrm{C}$ for 1 hour. The melting multi-layer crucible $\left(\varnothing 40 \mathrm{~mm} \times 80 \mathrm{~mm}\right.$ ) was manufactured as follows: firstly, a $\mathrm{ZrO}_{2} \cdot \mathrm{SiO}_{2} \mathrm{crucible}$ was produced by slip casting, using an emulsion similar to that used to make the pouring crucible, and fired at $1000^{\circ} \mathrm{C}$ for 1 hour to achieve the green strength necessary for manipulation and application of the $\mathrm{Y}_{2} \mathrm{O}_{3}$ layer. This layer was centrifugally applied for 1 hour at $1000 \mathrm{rpm}$ using an emulsion of $\mathrm{Y}_{2} \mathrm{O}_{3}$ in alcohol, commercially available from ZYP Coatings, USA (the solid component was $99.9 \% \quad \mathrm{Y}_{2} \mathrm{O}_{3}$, with grain size 1-6 $\left.\mu \mathrm{m}\right)$. Crucibles were then fired at different temperatures $\left(1400,1450\right.$ and $\left.1550^{\circ} \mathrm{C}\right)$ for 1 hour and cooled in the furnace to room temperature.

Melting and pouring. Melting charges of Ti48Al alloy weighing $1.3 \times 10^{-1} \mathrm{~kg}$ were prepared from CP Ti rod (with $0.23 \mathrm{wt} \% \mathrm{O}$ ) and $\mathrm{Al}$ fragments and melted in a Linn Hightherm $700 \mathrm{VAC}$ equipped with the manufactured ceramic crucible set. Before the heating cycle, the chamber was evacuated down to $10^{-3}$ mbar and back-filled with argon five times, in order to reduce the oxygen content to a minimum level. Melting was then performed under a controlled atmosphere of commercially pure dry argon at $0.05 \mathrm{mbar}$, using $1600^{\circ} \mathrm{C}$ and 60 seconds superheating temperature and time, respectively. Temperature was controlled with a type B thermocouple, protected by Mo$\mathrm{Al}_{2} \mathrm{O}_{3}-\mathrm{ZrO}_{2}$ refractory sheath. The melt was centrifugally poured at $400 \mathrm{rpm}$ into a graphite mould with $\varnothing 20 \times 120 \mathrm{~mm}$ cylindrical cavity, in order to assure that any oxygen contamination would result exclusively from the metal-crucible interaction during the melting operation. 
Crucibles characterization. Crucibles average porosity was evaluated according to the ISO Standard 5017:1998 (E). The $\mathrm{Y}_{2} \mathrm{O}_{3}$ layers were observed on a high-resolution FEI Quanta 400 FEG E Scanning Electron Microscope and images were used for image processing analysis in order characterize their porosity, using Image Pro Plus software. Alloy samples for characterization were collected from the middle of the cast cylinders by sectioning them at 50\% of their height. Phase identification and chemical composition evaluation were carried out on the same SEM equipment coupled to an EDAX Genesis X4M X-Ray Energy Dispersive Electron Spectrometer. The error associated to Ti and $\mathrm{Al}$ measurements was 0.2 at.\% and the error of $\mathrm{Y}$ measurement was 0.03 at.\%. Overall oxygen content was measured by the IGF technique (Inert Gas Fusion) on a Lecco TC-136 analyser, with an associated error of $20 \mathrm{ppm}$.

\section{Results and Discussion}

Fig. 1 presents the morphology of the $\mathrm{Y}_{2} \mathrm{O}_{3}$ layer: a), c) and e) show the surface of the layer for 1400, 1450 and $1550{ }^{\circ} \mathrm{C}$ sintering temperature, while b), d) and f) correspond to a fracture surface of the layer perpendicular to the surface shown in a), c) and e), for the same sintering temperatures. Fig. 1b), d) and f) clearly show a graded effect in grain size caused by the centrifugal operation. The smaller grains segregated to the internal surface of the coating (region where the yellow arrows are pointing to), while the larger ones segregated to the outside $\left(\mathrm{ZrO}_{2} \cdot \mathrm{SiO}_{2}\right.$ crucible-layer interface). After sintering, this graded effect led to a porosity gradient along the layers wall, as clearly seen in Figs 1b), d) and f). Fig. 1 shows fully sintered coating surfaces (crucible inner wall) with low porosity and an internal sintered region with much higher porosity. This coating morphology is extremely important to avoid or decrease the erosion of the crucible wall (among other factors it strongly depends on the crucible surface porosity) while maintaining high thermal shock resistance, which depends on the crucible/layer porosity. The average thickness of the yttria layers was $200 \pm 15 \mu \mathrm{m}$, as shown in Fig. 2 .
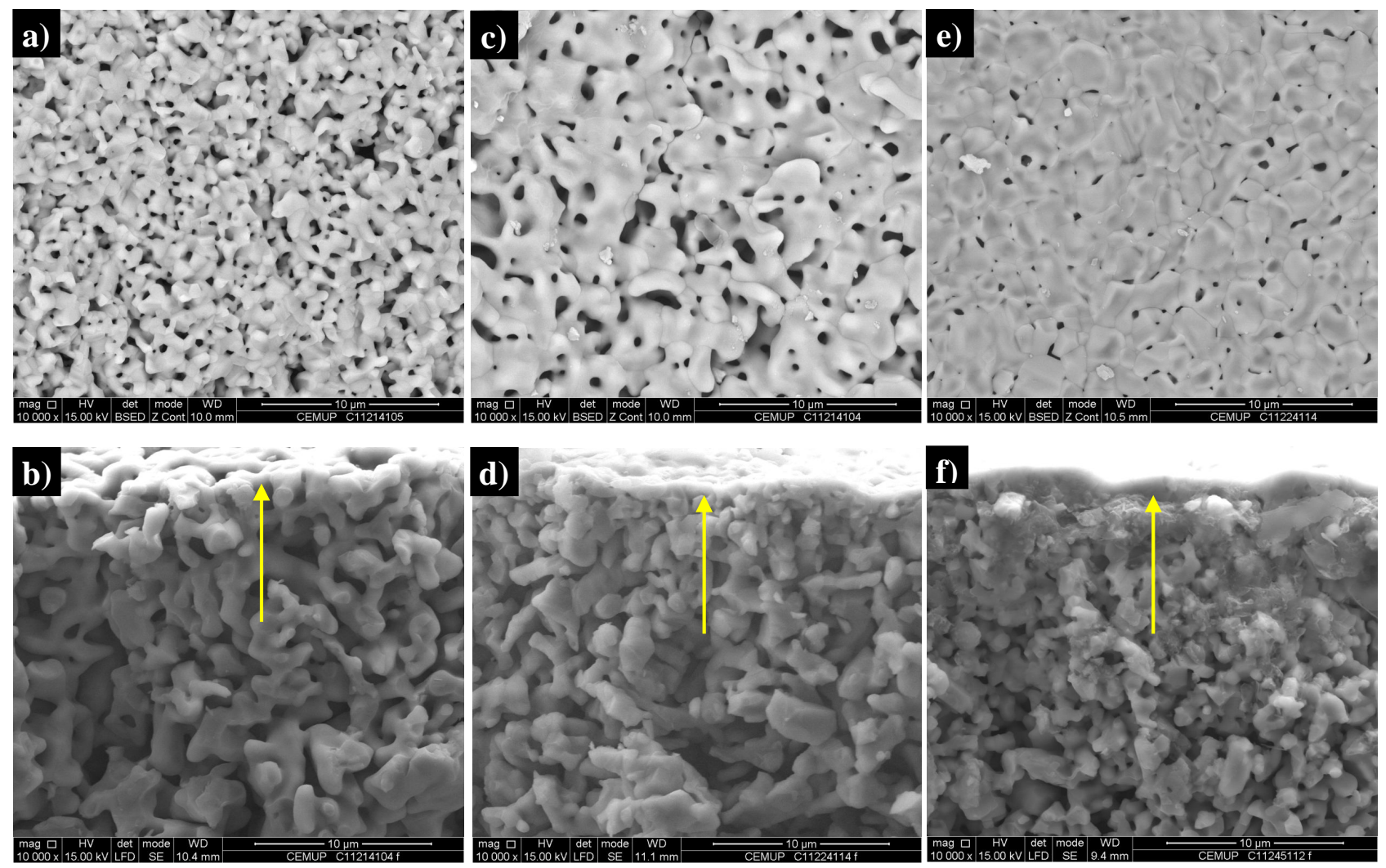

Fig.1 - External surface and fracture surface of $\mathrm{Y}_{2} \mathrm{O}_{3}$ layers fired at: a) and b) $1400^{\circ} \mathrm{C}$; c) and d) $1450^{\circ} \mathrm{C}$; e) and $\left.\mathrm{f}\right) 1550^{\circ} \mathrm{C}$, for 1 hour. The yellow arrows are pointing to the layers external surface, corresponding to Fig 1a), c) and e), which will contact the liquid alloy. 


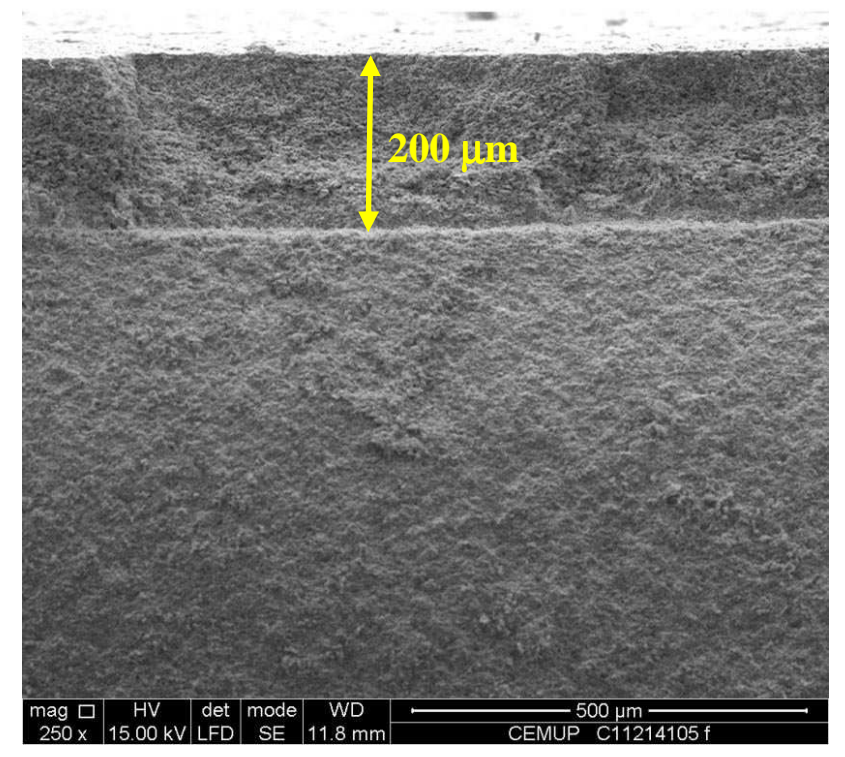

Fig.2 - Thickness of the $\mathrm{Y}_{2} \mathrm{O}_{3}$ layer on a crucible sintered at $1450^{\circ} \mathrm{C}$ for 1 hour.

Table 1 presents the crucibles average porosity and the surface porosity the $\mathrm{Y}_{2} \mathrm{O}_{3}$ layer. The effect of the sintering temperature in the layer and crucibles porosity is evident. Porosity decreased as the sintering temperature increased, for the same sintering time. In what concerns to the $\mathrm{Y}_{2} \mathrm{O}_{3}$ layer, the surface porosity decreased from an average value around $19.2 \%$ in those crucibles fired at $1400^{\circ} \mathrm{C}$ to an average value of $4 \%$ in those fired at $1550^{\circ} \mathrm{C}$ [Fig. 3a)]. Moreover, the pore size also decreased with increasing temperature, as a result of a much more significant coalescence and growth of the $\mathrm{Y}_{2} \mathrm{O}_{3}$ grains. In what concerns the $\mathrm{ZrO}_{2} \cdot \mathrm{SiO}_{2}$ crucible, the average porosity decreased from $37.7 \%$ for $1400^{\circ} \mathrm{C}$ sintering temperature to $29 \%$ for $1550^{\circ} \mathrm{C}$.

Table 1 - Effect of sintering temperature in the crucibles porosity and alloy contamination and microhardness.

\begin{tabular}{|c|c|c|c|c|c|c|c|}
\hline \multirow{2}{*}{$\begin{array}{c}\text { Melt } \\
\#\end{array}$} & \multirow{2}{*}{$\begin{array}{l}\text { Sintering } \\
\text { Temp. } \\
\left({ }^{\circ} \mathrm{C}\right)\end{array}$} & \multirow{2}{*}{$\begin{array}{l}\text { Crucibles } \\
\text { porosity } \\
(\%)\end{array}$} & \multirow{2}{*}{$\begin{array}{c}\mathrm{Y}_{2} \mathrm{O}_{3} \text { layer } \\
\text { surface porosity } \\
(\%)\end{array}$} & \multicolumn{2}{|c|}{$\begin{array}{l}\text { Alloy oxygen content } \\
\text { (wt. } \%)\end{array}$} & \multirow[t]{2}{*}{$\begin{array}{c}\mathrm{Y} \\
\text { (at.\%) }\end{array}$} & \multirow[t]{2}{*}{$\mathrm{HV}$} \\
\hline & & & & Enrichment $(*)$ & Final & & \\
\hline 1 & 1400 & 35 & 20.0 & 0.056 & 0.216 & 0.11 & 303 \\
\hline 2 & 1400 & 40 & 18.3 & 0.055 & 0.215 & 0.09 & 296 \\
\hline 3 & 1400 & 38 & 19.2 & 0.059 & 0.219 & 0.12 & 291 \\
\hline 4 & 1450 & 35 & 14.0 & 0.038 & 0.198 & n.a. & 289 \\
\hline 5 & 1450 & 37 & 12.6 & 0.038 & 0.195 & n.a. & 291 \\
\hline 6 & 1450 & 34 & 13.4 & 0.035 & 0.195 & n.a. & 293 \\
\hline 7 & 1550 & 29 & 4.0 & 0.026 & 0.186 & n.a. & 293 \\
\hline 8 & 1550 & 32 & 4.3 & 0.032 & 0.192 & n.a. & 289 \\
\hline 9 & 1550 & 26 & 3.6 & 0.028 & 0.188 & n.a. & 293 \\
\hline
\end{tabular}

(*) Calculated assuming that the maximum $\mathrm{O}$ content due to the melting stock was $0.16 \%$ [11] n.a. Below the equipment detection limit

The $\mathrm{Y}_{2} \mathrm{O}_{3}$ layer porosity played a major role in the residual contamination of the Ti48Al alloys. Every alloy was found to be contaminated with oxygen, whose concentration increased directly with the layer porosity, as presented in Table 1 and Fig.3b). The oxygen content in the alloys was higher than that attributed to the oxygen present in the constituents of the melting stock $(0.16 \mathrm{wt} \%$ max.) revealing that "oxygen enrichment" have occurred. Since the entire processing was performed under a dry argon atmosphere, reducing the possibility of oxygen pick-up, the only source of oxygen in the melting chamber was the crucible material. According to its free energy of formation, $\mathrm{Y}_{2} \mathrm{O}_{3}$ is more stable than $\mathrm{Ti}$ and $\mathrm{Al}$ oxides, excluding the possibility of metal-crucible reaction. Therefore, the most probable cause for the detected "oxygen enrichment" was the 
dissolution of the yttria layer by the molten alloy, confirming the results of previous work of the authors [11,12] and other researchers [13]. Besides oxygen, those samples melted in crucibles with higher layer porosity (melts 1, 2 and 3) were also contaminated with Y, which approximate average content was 0.11 at $\%$. Moreover, those samples also revealed the presence of small particles of $\mathrm{Y}_{2} \mathrm{O}_{3}$ dispersed in the matrix (Fig.4), suggesting that besides dissolution, erosion of the $\mathrm{Y}_{2} \mathrm{O}_{3}$ layer might also have occurred. Those samples cast in crucibles with layers of lower porosity (melts 4 -9) didn't reveal the presence of $\mathrm{Y}$ in solution, although its presence can't be excluded since the concentration may be lower than the SEM/EDS detection limit (0.05 at.\%). Furthermore, in those samples the presence of dispersed $\mathrm{Y}_{2} \mathrm{O}_{3}$ particles was not detected. No $\mathrm{Zr}$ or zircon particles were found in the cast samples, revealing that $\mathrm{Y}_{2} \mathrm{O}_{3}$ is an effective barrier against the molten TiAl alloy. Moreover, with exception of those crucibles with $\mathrm{Y}_{2} \mathrm{O}_{3}$ layer with lower porosity, where thin cracks have been found, no cracks were detected in the crucibles or the inner layers after pouring.

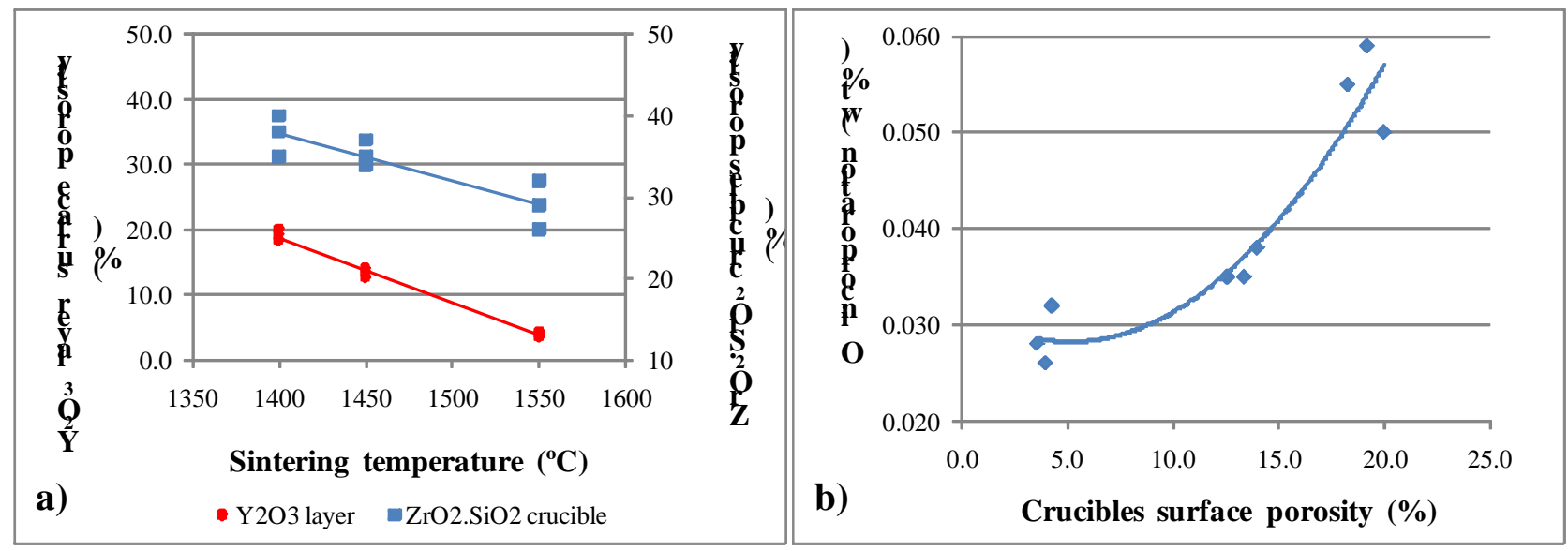

Fig.3 a) Influence of sintering temperature on the surface porosity of the $\mathrm{Y}_{2} \mathrm{O}_{3}$; b) Effect of $\mathrm{Y}_{2} \mathrm{O}_{3}$ surface porosity on the oxygen incorporation in molten Ti48Al alloys.

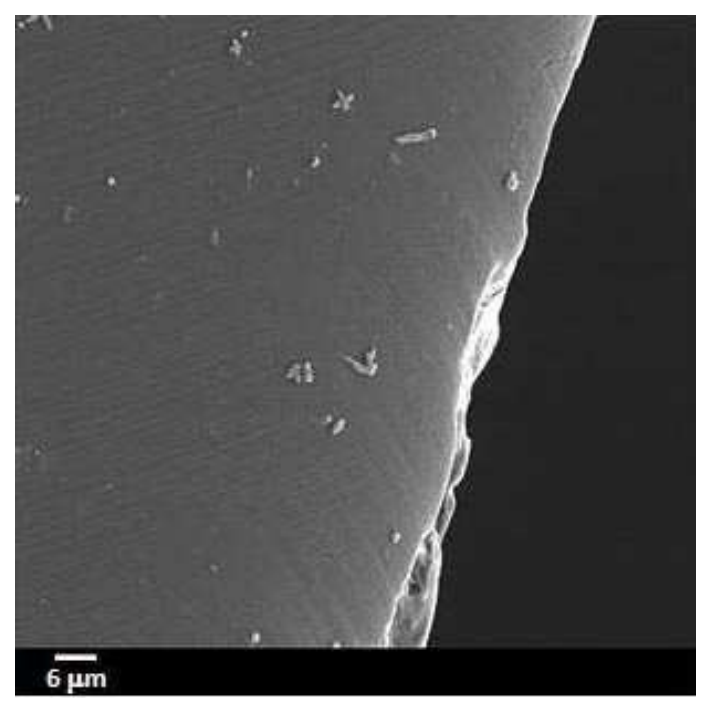

Fig.4 Yttria particles dispersed in the Ti48Al matrix, as a result of erosion of the crucible's $\mathrm{Y}_{2} \mathrm{O}_{3}$ inner layer

The most probable cause of erosion of the yttria layers with higher porosity might have been the combination of two factors: easier penetration of the molten alloy in the interstices between $\mathrm{Y}_{2} \mathrm{O}_{3}$ grains, detachment of some of them and consequent partial or full dissolution in the melt, and the melt stirring caused by the electromagnetic field. Detachment of $\mathrm{Y}_{2} \mathrm{O}_{3}$ grains didn't occur in those layers with lower porosity due to their more reduced pore size, that prevented metal penetration, for the melt viscosity verified on this work. Since both O and Y content of the alloys decreased with increasing layer porosity, it seems evident that the extension of the layer dissolution depended on the contact surface between the alloy and the $\mathrm{Y}_{2} \mathrm{O}_{3}$ grains, which was higher in those 
layers with higher porosity, since metal penetration could more easily occur. This fact suggests that metal penetration was the most important mechanism involved in the alloys contamination with $\mathrm{O}$ and $\mathrm{Y}$.

Nevertheless, O contamination was much lower than that observed in former works developed by the authors and other researchers, and was the lowest obtained so far in the ceramic crucible induction melting process [7-14].

\section{Conclusions}

- A $\mathrm{ZrO}_{2} \cdot \mathrm{SiO}_{2}$ based crucible with inner $\mathrm{Y}_{2} \mathrm{O}_{3}$ layer was developed to melt TiAl based alloys, and can lead to $\mathrm{O}$ contamination less than $0.03 \mathrm{wt} \%$;

- $\mathrm{O}$ contamination depends on the porosity of the inner $\mathrm{Y}_{2} \mathrm{O}_{3}$ layer, and increases directly with it. For a fixed sintering time, the porosity of the $\mathrm{Y}_{2} \mathrm{O}_{3}$ layer depends on the sintering temperature;

- $\mathrm{O}$ contamination is due to the dissolution of the $\mathrm{Y}_{2} \mathrm{O}_{3}$ layer, which is potentiated by metal penetration that may occur when the layer porosity is higher than $14 \%$;

- Some cracks can develop after melting in $\mathrm{Y}_{2} \mathrm{O}_{3}$ layers with porosity around $4 \%$, but that has no influence on the final $\mathrm{O}$ content in the alloy.

\section{References}

[1] S.R. Wang et al., Centrifugal precision cast TiAl turbochargerwheel using ceramic mold. J. Mat. Proc. Tech. 204 (2008) 492-497.

[2] T. Tetsui, Development of TiAl turbocharger for passenger vehicle. Mat. Sci. Eng. A 329-331 (2002) 582-588.

[3] W.F. Cui et al., Thermomechanical fatigue behaviour of a third generation gamma-TiAl based alloy. Intermetallics 15 (2007) 675-678.

[4] F.H.Froes et al., Titanium in the family automobile - the cost challenge. JOM 56 (2) (2004) 4044.

[5] F.H Froes et al., Cost-affordable titanium - the component fabrication perspective. JOM 59 (6) (2007) 28-31.

[6] C. Frueh et al., Attempts to develop a ceramic mould for titanium casting - a review. International Journal of Cast Metals Research 9 (4) (1996) 233-240.

[7] F. Gomes et al., Induction melting of $\gamma$-TiAl in $\mathrm{CaO}$ crucibles. Intermetallics 16 (2008) 12921297.

[8] Liu et al., Single step centrifugal casting TiAl automotive valves. Intermetallics 13 (2005) 925928.

[9] T. Sato et al., A new process of producing titanium alloy castings. Trans Jpn Foundrym Soc 11 (1992) 27-33.

[10]L. Aihui et al, Study of interface reactions between TiAl alloys and four ceramic molds. Rare Met Mater Eng 37 (6) (2008) 956-959.

[11] J. Barbosa et al., Influence of superheating on casting of gamma TiAl. Intermetallics 15 (2007) 945-955

[12] J. Barbosa et al., Evaluation of $\mathrm{Y}_{2} \mathrm{O}_{3}$ as front layer of ceramic crucibles for vacuum induction melting of TiAl based alloys: Proc. EPD Congress 2005 (2005 TMS Annual Meeting). S. Francisco, USA: TMS, 2005, 573-584.

[13]C. Renjie et al., Interactions between TiAl alloys and yttria refractory material in casting process. J Mat Proc Tech 210 (2010) 1190-1196.

[14]A.V. Kartavykh et al., TiAl-Nb melt interaction with pyrolytic boron nitride crucibles. Mat Chem Phys 119 (2010) 347-350.

[15] A.V. Kartavykh et al., TiAl-Nb melt interaction with AlN refractory crucibles. Mat Chem Phys 116 (2009) 300-304. 